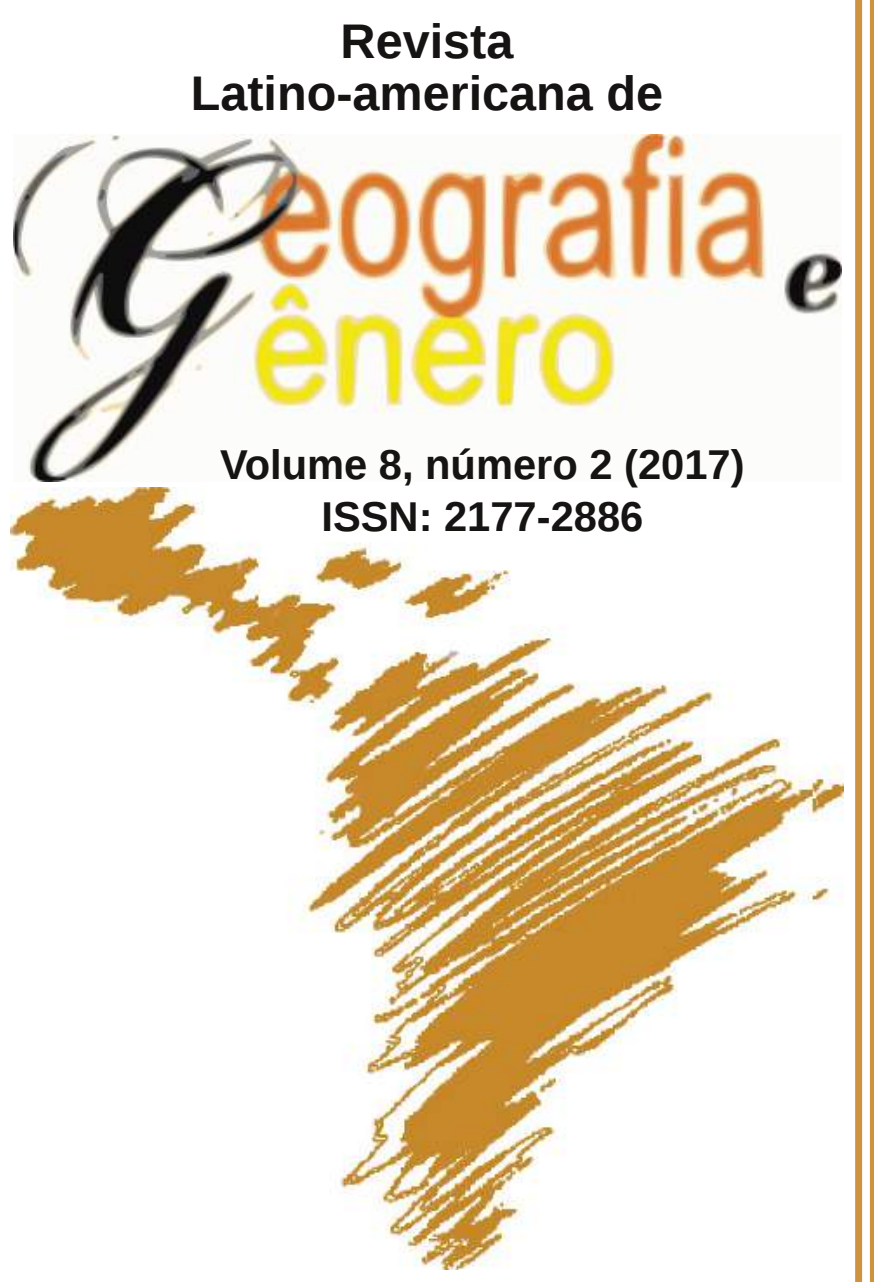

\title{
'Geografias Lésbicas: Gênero, Lugar e Poder" de Kath Browne e Eduarda Ferreira
}

'Geografías Lesbianas: Género, Lugar y Poder' de Kath Browne y Eduarda Ferreira

'Lesbian Geographies: Gender, Place and Power' by Kath Browne and Eduarda Ferreira

\author{
Joseli Maria Silva \\ Universidade Estadual de Ponta Grossa - Brasil \\ joseli.genero@gmail.com

\section{Marcio Jose Ornat} \\ Universidade Estadual de Ponta Grossa - Brasil \\ geogenero@gmail.com
}

Como citar:

SILVA, Joseli Maria; ORNAT, Marcio Jose. Resenha: Geografias Lésbicas: Gênero, Lugar e Poder de Kath Browne e Eduarda Ferreira. Revista Latino Americana de Geografia e Gênero, v. 8, n. 2, p. 376378, 2017. ISSN 2177-2886.

Disponível em:

http://www.revistas2.uepg.br/index.php/rlagg 
O livro 'Geografias Lésbicas: gênero, lugar e poder' (Lesbian Geographies: gender, place and power) organizado por Kath Browne e Eduarda Ferreira é uma obra rara. Não apenas porque ela questiona a invisibilidade das experiências espaciais de mulheres lésbicas no conhecimento geográfico, mas, sobretudo, porque é uma obra que nos faz questionar as limitações epistemológicas de nosso campo de saber científico, desafiando formas tradicionais de pensar o espaço e instigando outras imaginações geográficas possíveis. Outra importante característica da excepcionalidade deste livro é seu caráter político de contestação das hegemonias. Além de questionar o protagonismo masculino na produção científica das geografias das sexualidades, também se preocupa em desestabilizar o poder anglófono na produção científica das geografias lésbicas. A obra apresenta uma importante pluralidade temática sobre as vivências espaciais das mulheres lésbicas, bem como explora diferentes contextos culturais resultantes da multiplicidade das autorias provenientes de lugares para além do mundo anglo-americano. É assim que esta obra deve ser interpretada, pois apesar de ser um livro escrito em inglês, a obra traz a riqueza das possibilidades de compreensão da relação entre lugares, sexualidades e gênero.

O primeiro capítulo, desenvolvido pelas organizadoras, se dedica a posicionar o surgimento desse campo disciplinar, bem como esclarecer as intencionalidades da obra no que diz respeito à compreensão das identidades lésbicas e suas imbricações com os espaços e tempos. As autoras evidenciam que a criação das geografias lésbicas se deu pela necessidade, de um lado, de superar o protagonismo feminino heterossexual e, por outro, pelo enfrentamento da hegemonia de homens gays nas geografias das sexualidades. As geografias lésbicas nascem, portanto, pela luta contra a invisibilidade das vivências lésbicas em ambos os campos epistemológicos, feminista e das sexualidades, no contexto de produção científica anglófona nos anos 1980 . Assim, a perspectiva das geografias lésbicas se pauta desde o início pela interseção entre gênero e sexualidades, trazendo como preocupação a forma como estas interseções ocorrem na relação com diferentes espaços e tempos.

Kath Browne e Eduarda Ferreira negam a visão essencializada das identidades lésbicas, provocando os leitores para pensar a necessidade de interpretações identitárias fluidas e dependentes de suas relações espaciais. Segundo elas, as liberdades sexuais e de gênero são construídas relacionalmente, pois o espaço é um elemento central da construção identitária e das formas como nossas vidas são vividas. Sendo assim, elas alegam que o espaço é mais do que um pano de fundo para constituição de nossas identidades, mas ele desempenha um papel ativo na sua constante reconstrução. Kath Browne e Eduarda Ferreira consideram que é impossível obter uma noção universal do que seja 'ser lésbica', pois tal compreensão depende de uma série de outras relações que são parte constituinte do ser humano como classe, raça, idade e espaço. Contudo, argumentam elas, o termo 'lésbica' é utilizado para denunciar relações de poder em espaços específicos e esse reconhecimento político do termo deve ser considerado, mesmo que elas neguem haver uma cultura global única e um referente fixo do que seja 'ser lésbica'.

Nessa trajetória de argumentos o livro, com a colaboração de diversas 
autoras que escrevem os capítulos seguintes, traz a pluralidade de abordagens e críticas de várias partes do mundo para além da produção científica do norte global, enriquecendo ainda mais as múltiplas possibilidades de compreensão do termo 'lésbica'. Os capítulos que se seguem exploram contextos como Hungria, Canadá, Israel, Reino Unido, Nova Zelândia, Rússia, Polônia, França, Austrália e Estados Unidos. Além disso, os diferentes capítulos consideram variadas escalas espaciais para suas análises, como o espaço doméstico, o corpo, a cidade e a nação, evidenciando a profunda relação entre espaço, gênero e sexualidades.

O livro traz uma contribuição analítica de Catherine Nash que apela para a produção de visibilidades, o direito das pessoas serem reconhecidas pelo que são e, ainda para ação política da produção científica. De forma entusiástica Catherine fala sobre os capítulos precedentes que compõem o livro chamando atenção para o marco que a obra representa para inaugurar uma trajetória científica a ser reforçada. Além disso, com base nos elementos que ela considerou serem comuns nas discussões presentes no livro como as identidades, os lugares e as exclusões, ela aponta caminhos para ampliação da discussão da existência espacial de mulheres lésbicas. Sua perspectiva de compreensão de identidades em permanente movimento de negociação política traz os tensionamentos intergeracionais, escalares e interseccionais como desafios para constituir saberes complexos que corroborem para construção de vidas vivíveis e de justiça social.

As identidades lésbicas são múltiplas, geográfica e temporalmente instáveis, pois são profundamente marcadas pelas negociações políticas de várias naturezas. O espaço é um dos elementos marcantes na constituição das negociações identitárias, já que os lugares possibilitam a experiência das pessoas que se reconhecem em determinadas identidades. Os processos de negociação escalares ocorrem em processo de contestação, resistência e conflitos ou, ainda, em forma de cooperação e arranjo de mutualidade e harmonia. O poder e seus diversos eixos em múltiplas direções criam arranjos espaciais complexos promovendo simultaneamente inclusão e exclusão de diferentes grupos sociais que estão sob a bandeira das chamadas 'minorias sexuais'.

Enfim, esta obra que retrata as 'geografias lésbicas' é uma imensa contribuição ao enriquecimento da epistemologia da ciência geográfica como um todo e, ao mesmo tempo, um convite para o desenvolvimento de caminhos que foram aqui apontados. Mas, acima de tudo, a nosso ver, o livro desencadeia uma inquietude sobre as necessidades de alargarmos os limites da produção do conhecimento a fim de criar mundos vivíveis que contemplem nossa diversidade de desejos e prazeres humanos.

\section{Referências}

BROWNE, Kath; FERREIRA, Eduarda. Lesbian Geographies: gender, place and power. Farnham: Ashgate Publishing Limited, 2015.

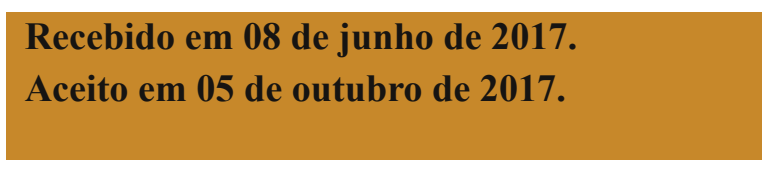

